\title{
On an invariant of a non-stationary model of pipelines gas flow
}

\author{
Pyanylo Ya. ${ }^{1}$, Prytula N. ${ }^{2}$, Prytula M. ${ }^{2}$, Khymko O. ${ }^{1}$ \\ ${ }^{1}$ Centre of Mathematical Modelling of Pidstryhach Institute for \\ Applied Problems of Mechanics and Mathematics, NAS of Ukraine, \\ 15 Dudayev Str., 79005, Lviv, Ukraine \\ ${ }^{2}$ Department of Disigning Systems of Optimal Scheduling and Forecasting Operating Modes of GTS, \\ Research and Design Institute of Gas Transport of PJSC "Ukrtransgaz", \\ 16 Koniev Str., 61004, Kharkiv, Ukraine
}

(Received 22 December 2018; Revised 23 April 2019; Accepted 25 April 2019)

\begin{abstract}
A problem of gas balance analysis in the gas transportation system objects and the factors of influence on the accuracy of its installation are considered. It is shown that the problem of accuracy of calculation of the individual balance indicators can be effectively solved. For this purpose, the invariants of the mathematical model of gas flow are used. The carried out computational experiments have confirmed the sufficient accuracy of the suggested approach.
\end{abstract}

Keywords: gas balance, gas pipeline tightness, algorithmic method, gas leakages, gas flow mathematical model.

2000 MSC: $76 \mathrm{~N} 25,49 \mathrm{~J} 20$

UDC: $622.692 .4+622.691 .24$

DOI: $10.23939 / \mathrm{mmc} 2019.01 .116$

\section{Introduction}

Decisions-making by the dispatching services of gas transportation systems are based on the gas balance analysis in subsystems of the gas transportation system (GTS) which are closed by the gas consumption measurements. Gas balance is formed on the basis of gas consumption volumes measurements: for extraction, underground storages, transitional and imported flows; for distribution between consumers, and for injection into underground storages. In addition, it is also necessary to take into account the volumes (and their changes) of accumulated gas in technological facilities of the GTS, the gas consumptions for technological and own needs, gas losses due to the nontightness of the objects of the GTS, etc.

Indicators used in the gas balance calculation are normative, calculated and measured values that differ from the actual by the errors of normalization, calculations and measurements of gas consumption. The set of these errors forms the total amount of imbalance, i.e., the imbalance is the sum of components on the objects of the GTS and by types of sources of imbalance. The imbalance sources can be divided into unrecorded losses, and also instrumental and methodological errors of gas flow determination. The accepted methods of gas consumptions and losses normalization in the GTS equipment are reduced to the measurement and calculations of consumptions for the equipment unit and are adjusted for different modes of operation and technical condition of the equipment. A standard approach with the use of full accurate accounting of all calculated or measured components is impossible. It is necessary to develop a method for estimating the imbalance in the conditions of incompleteness and uncertainty of the information for the components of the imbalance. Consider one of the important factors that affect the gas imbalance in the GTS.

It is known that in the process of operation of high-pressure main gas pipelines, their depressurization can occur. In this case mainly whistles appear on welded joints and light cranes. If among a plurality of leaks one or several which make a major contribution to the total leakage stands out then the problem of identifying them by size and location can be set. 
It is obvious that gas leaks are insignificant compared to the volumes of the transported gas. Therefore, to determine the gas leakages, it is necessary to have a sufficiently accurate model of the gas flow in the pipeline and a sufficient number of measured data to identify the size and location of the leak. The accuracy of the model is influenced by many factors. Among them there should excrete a certain degree of uncertainty in the establishment of model parameters - hydraulic resistance, heat transfer coefficient, gas-external environment, soil temperature in the vicinity of the pipeline, etc. All specified parameters are distributed along the laying of pipelines, whose length is often more than a hundred kilometers. Moreover, these parameters depend nonlinearly on the type and humidity of the soil, multifold local resistances, pipeline laying path, the nature of the gas flow, etc., which cannot be fully taken into account. In such cases, there are also averaging errors of the model parameters.

The above motivates to carrying out the work to establish invariants of stationary and nonstationary models, which would exclude as much as possible the influence of individual weakly determined factors on the accuracy of calculations of balance indicators.

There are a lot of different methods for leaks locating and their magnitude estimating [1-7]. A significant amount of them, which requires complex technical equipment, is quite expensive. As carried out by well-known specialized firms researches have shown the technical means are capable to detect and localize about $10 \%$ of the gas leakages. Therefore, the development of simple and relatively cheap means of estimating and locating leakages in the GTS remains relevant.

\section{Analysis of influence of parameters of the gas motion stationary model on the balance regime values calculation}

The difference between volumetric gas consumptions at the inlet and outlet of the gas pipeline at a certain time interval can serve as an estimate of leaks volumes from the gas pipeline. Let us consider the following problem.

As the boundary conditions, to determine the pressure distribution in the pipeline, we take the pressure functions dependent on time. Let us find the difference between volumetric input and output gas consumptions. From the gas state equation $p=m z R T / q$ volumetric gas consumptions at the inlet and outlet of the pipeline are determined by the formulas $q_{v x}=\frac{m}{p_{v x}} z_{v x} R T_{v x}$ and $q_{v y x}=\frac{m}{p_{v y x}} z_{v y x} R T_{v y x}$ in accordance. Here $m$ and $q$ are mass and volume respectively. Then $q_{v y x}-q_{v x}=\frac{m}{p_{v y x}} z_{v y x} R T_{v y x}-$ $\frac{m}{p_{v x}} z_{v x} R T_{v x}$.

If to calculate the compression coefficient we use the formula $[8,9]$

$$
z=\frac{1}{1+f p}
$$

where $p$ is measured in atmospheres, $f=\left(24-0.21 t^{\circ} \mathrm{C}\right) \cdot 10^{-4}$, and $t^{\circ} \mathrm{C}$ is the gas temperature for Celsius, which, with a sufficient for practice accuracy describes the difference between the real and ideal gas, then

$$
q_{v y x}-q_{v x}=\frac{m}{p_{v y x}} \frac{1}{1+f p_{v y x}} R T_{v y x}-\frac{m}{p_{v x}} \frac{1}{1+f p_{v x}} R T_{v x} .
$$

We will assume that the gas flow is stationary and the output pressure is determined by the formula [8$10]$

$$
p_{v y x}=\sqrt{p_{v x}^{2}-\frac{\lambda l z R T}{D}\left(\frac{M}{F}\right)^{2}}
$$

Because

$$
\sqrt{p_{v x}^{2}-\frac{\lambda l z R T}{D}\left(\frac{M}{F}\right)^{2}}=p_{v x}\left(1-\frac{\lambda l z R T}{D p_{v x}^{2}}\left(\frac{M}{F}\right)^{2}\right)^{1 / 2} \approx p_{v x}\left(1-\frac{\lambda l z R T}{2 D p_{v x}^{2}}\left(\frac{M}{F}\right)^{2}\right),
$$

Mathematical Modeling and Computing, Vol. 6, No. 1, pp. 116-128 (2019) 
then after identical transformations we get

$$
\Delta q=\frac{m R}{p_{v x}}\left[T_{v y x}-T_{v x}-f\left(T_{v y x} p_{v y x .0}-T_{v x} p_{v x, 0}\right)+\frac{\lambda l z R T T_{v y x}}{2 D p_{v x}^{2}}\left(\frac{M}{F}\right)^{2}\left(1-f p_{v y x .0}\right)\right] .
$$

The last formula shows that for given boundary conditions for pressure the difference between the volumetric consumptions between the input and the output insignificantly depends on the parameters of the model, and to a large extent only on the boundary conditions. The carried out experiments have shown that this difference is insignificant compared to the volumetric gas consumption.

The hydraulic resistance coefficient $\lambda$ depends on the roughness coefficient of the inner wall of the pipeline $k_{r}$, the internal diameter of the pipeline $D_{f}$ and the Reynolds number $R e$, that is $\lambda=$ $\lambda\left(R e, D, k_{r}\right)$, in particular [10]

$$
\lambda=\left(\frac{Y+\varepsilon+C^{1.5}}{1+76 C}\right)^{0.2}, \quad \varepsilon=\frac{k_{r}}{D}, \quad Y=\frac{79}{R e}, \quad C=(2 Y)^{10} .
$$

The coefficient of hydraulic resistance $\lambda$ is insignificantly influenced by the roughness coefficient, provided that the inequality is fulfilled;

$$
\frac{k_{r}}{D}=\frac{79 v}{v D} \quad k_{r}=\frac{79 v}{v} .
$$

If $v$ is the average speed, then for methane $v=0.000015 \mathrm{~Pa}$ and insignificant dependence will be executed

$$
k_{r}=\frac{0.001185}{v} \text {. }
$$

\section{An analysis of the influence of parameters of a non-stationary gas flow model on the balance regime values calculation}

The mathematical model of gas transportation by the main gas pipelines (MGP) with CS's and concentrated inflows and outflows can be presented using generalized functions [8-11]

$$
\left\{\begin{array}{l}
\frac{\partial \omega}{\partial t}+\frac{\partial p}{\partial x}+a \omega-b p=\Theta(x, t) \\
\frac{\partial \omega}{\partial x}+\frac{1}{c^{2}} \frac{\partial p}{\partial t}=\Psi(x, t)
\end{array}\right.
$$

The functions

$$
\Theta(x, t)=\sum_{i=1}^{I} p_{s t, i} \delta\left(x-x_{i}\right)\left[\eta\left(t-t_{1 i}\right)-\eta\left(t-t_{2 i}\right)\right]
$$

and

$$
\Psi(x, t)= \pm \sum_{j=1}^{J} \frac{q_{j}(t)}{F} \delta\left(x-x_{j}\right)\left[\eta\left(t-t_{1 j}\right)-\eta\left(t-t_{2 j}\right)\right]
$$

take into account the availability of compressor stations at points $x=x_{i}, i=\overline{1, I}$ and leakage $\left(p, q, t_{1 j}, t_{2 j}\right)$ at points $x=x_{j}, j=\overline{1, J}$, with the turning-on times $t_{1 i}, t_{1 j}$ and turning-off times $t_{2 i}, t_{2 j}$ respectively. In the formula (3) $F$ is the cross-sectional area of the pipeline, sign $(+)$ indicates the gas extraction, and sign (-) indicates the gas injection.

To formulate the boundary value problem, it is necessary to set the boundary conditions for the pressure function

$$
p(0, t)=p_{0 k}(t), \quad p(l, t)=p_{k k}(t),
$$

or for the mass consumption function

$$
\omega(0, t)=\omega_{0 k}(t), \quad \omega(l, t)=\omega_{k k}(t) .
$$

Mathematical Modeling and Computing, Vol. 6, No. 1, pp. 116-128 (2019) 
As the initial condition, a known stationary pressure distribution is adopted $p(x, 0)=p_{0 m}(x)$, or a stationary mass consumption distribution $\omega(x, 0)=\omega_{0 m}(x)$. Let us pass to the images of LaplaceCarson [12] in the system (1)

$$
\left\{\begin{array}{c}
(s+a) \bar{\omega}+\frac{d \bar{p}}{d x}-b \bar{p}=s \omega_{0 m}+\bar{\Theta} \\
\frac{d \bar{\omega}}{d x}+\frac{s}{c^{2}} \bar{p}=\frac{s}{c^{2}} p_{0 m}+\bar{\Psi}
\end{array}\right.
$$

where $s$ is the Laplace transform parameter, $\bar{p} \equiv \bar{p}(x, s), \bar{\omega} \equiv \bar{\omega}(x, s), \bar{\Theta} \equiv \bar{\Theta}(x, s)$ and $\bar{\Psi} \equiv \bar{\Psi}(x, s)$ is the Laplace-Carson image of corresponding originals. In particular, when $q_{j}(t)=q_{j} \equiv$ const, we will get

$$
\begin{aligned}
& \bar{\Theta}(x, s)=\sum_{i=1}^{I} p_{s t, i} \delta\left(x-x_{i}\right)\left[e^{-t_{1 i} s}-e^{-t_{2 i} s}\right], \\
& \bar{\Psi}(x, s)=\sum_{j=1}^{J} \frac{q_{j}}{F} \delta\left(x-x_{j}\right)\left[e^{-t_{1 j} s}-e^{-t_{2 j} s}\right] .
\end{aligned}
$$

For stable boundary and initial conditions instead of functions $\bar{p}$ and $\bar{\omega}$ it is expedient to introduce functions

$$
\overline{\hat{p}}=\bar{p}+\frac{x}{l} h_{p}-p_{0 k}, \quad \overline{\hat{\omega}}=\bar{\omega}+\frac{x}{l} h_{\omega}-\omega_{0 k},
$$

where $h_{p}=p_{0 k}-p_{k k}, h_{\omega}=\omega_{0 k}-\omega_{k k}$. Functions $\overline{\hat{p}}$ and $\overline{\hat{\omega}}$ satisfy the zero boundary conditions. In the new symbols, system (4) will look

$$
\left\{\begin{array}{l}
(s+a) \overline{\hat{\omega}}+\frac{d \overline{\hat{p}}}{d x}-b \overline{\hat{p}}=\phi_{1}, \\
\frac{d \overline{\hat{\omega}}}{d x}+\frac{s}{c^{2}} \overline{\hat{p}}=\phi_{2},
\end{array}\right.
$$

where

$$
\phi_{1}=s \omega_{o m}-(s+a) \omega_{0 k}+\frac{1}{l} h_{p}+b p_{0 k}+\bar{\Theta}(x, s)+\frac{x}{l}\left[(s+a) h_{\omega}-b h_{p}\right]
$$

and

$$
\phi_{2}=\frac{s}{c^{2}} p_{o n}+\frac{1}{l} h_{\omega}-\frac{s}{c^{2}} p_{o n}+\bar{\Psi}(x, s)+\frac{x}{l} \frac{s}{c^{2}} p_{\text {om }} h_{p} .
$$

The system (8) is solved by the separating variables method by sines [9], i.e.

$$
\left\{\begin{array}{l}
\overline{\hat{p}}(x, s) \\
\hat{\omega}(x, s)
\end{array}\right\}=\sum_{n=1}^{\infty}\left\{\begin{array}{c}
\overline{\hat{p}}_{n}(s) \\
\hat{\omega}_{n}(s)
\end{array}\right\} \sin \frac{n \pi x}{l},
$$

where the Fourier coefficients

$$
b_{n}=\left\{\begin{array}{c}
\overline{\hat{p}}_{n}(s) \\
\hat{\hat{\omega}}_{n}(s)
\end{array}\right\}
$$

of functions

$$
b(x)=\left\{\begin{array}{c}
\overline{\hat{p}}(x, s) \\
\hat{\hat{\omega}}(x, s)
\end{array}\right\}
$$

If

$$
\hat{b}_{n}=\frac{1}{l} \int_{0}^{l} b(x) e^{-n \pi i x / l} d x
$$

then

$$
b_{n}=-2 \operatorname{Im}\left\{\hat{b}_{n}\right\}
$$


If we integrate equations (12) by parts, then we will get

$$
\hat{b}_{n}=\nu_{n} \int_{0}^{l} \frac{d b(x)}{d x} e^{-\frac{x}{\nu_{n} l}} d x
$$

From the system (8) we will get

$$
\left\{\begin{array}{l}
\frac{d \overline{\hat{p}}}{d x}=\phi_{1}+b \overline{\hat{p}}-(s+a) \overline{\hat{\omega}} \\
\frac{d \hat{\hat{\omega}}}{d x}=\phi_{2}-\frac{s}{c^{2}} \overline{\hat{p}} .
\end{array}\right.
$$

From the formulas (14) and (15)

$$
\overline{\hat{p}}(s)=\nu_{n} l\left[\phi_{1 n}+b \overline{\hat{p}}_{n}(s)-(s+a) \overline{\hat{\omega}}_{n}(s)\right],
$$

and

$$
\overline{\hat{\omega}}_{n}(s)=\nu_{n} l\left[\phi_{2 n}-\frac{s}{c^{2}} \overline{\hat{p}}_{n}(s)\right] .
$$

If we mark $\kappa_{n}=\left(1-b l \nu_{n}\right) /\left(\nu_{n} l / c\right)^{2}$, then

$$
\overline{\hat{p}}_{n}(s)=-\left(\frac{c}{\nu_{n} l}\right)^{2} \nu_{n} l \frac{\phi_{1 n}-\nu_{n} l(s+a) \phi_{2 n}}{\left(s-s_{1}\right)\left(s-s_{2}\right)},
$$

where

$$
s_{1}=\frac{1}{2}\left(-a-\sqrt{a^{2}-4 \kappa_{n}}\right), \quad s_{2}=\frac{1}{2}\left(-a+\sqrt{a^{2}-4 \kappa_{n}}\right) .
$$

The coefficients $\phi_{1 n}$ and $\phi_{2 n}$ look like

$$
\phi_{1 n}=\hat{\hat{\nu}}_{n}\left[(s+a) h_{\omega}-b h_{p}\right]+\hat{\nu}_{n}\left[s \omega_{o m}-(s+a) \omega_{o k}+\frac{1}{l} h_{p}+b p_{0 k}\right]+\bar{\Theta}_{n}(s),
$$

and

$$
\phi_{2 n}=\hat{\hat{\nu}}_{n} \frac{s}{c^{2}} h_{p}+\hat{\nu}_{n}\left[\frac{s}{c^{2}}\left(p_{\text {om }}-p_{\text {on }}\right)+\frac{1}{l} h_{\omega}\right]+\bar{\Psi}_{n}(s) .
$$

If we substitute the expressions for $\phi_{1 n}$ and $\phi_{2 n}$ in formula (18) and introduce the notation

$$
\begin{aligned}
& d_{1}=\hat{\hat{\nu}}_{n}\left(a h_{\omega}-b h_{p}\right)+\hat{\nu}_{n}\left(\frac{1}{l} h_{p}+b p_{o k}-a \omega_{o k}\right)-a \nu_{n} \hat{\nu}_{n} h_{\omega}, \\
& d_{2}=\hat{\hat{\nu}}_{n} h_{\omega}+\hat{\nu}_{n}\left(\omega_{o m}-\omega_{o k}\right)-\nu_{n} l\left(\frac{1}{l} \hat{\nu}_{n} h_{\omega}+\frac{a}{c^{2}}\left(\hat{\hat{\nu}}_{n} h_{p}+\hat{\nu}_{n}\left(p_{o m}-p_{o k}\right)\right)\right), \\
& d_{3}=-\nu_{n} l \frac{1}{c^{2}}\left(\hat{\hat{\nu}}_{n} h_{p}+\hat{\nu}_{n}\left(p_{o m}-p_{o k}\right)\right),
\end{aligned}
$$

then we will get

$$
\overline{\hat{p}}_{n}(s)=-\left(\frac{c}{\nu_{n} l}\right)^{2} \frac{\nu_{n} l}{\left(s-s_{1}\right)\left(s-s_{2}\right)}\left\{d_{1}+s d_{2}+s^{2} d_{3}+\bar{\Theta}_{n}(s)-\nu_{n} l(s+a) \Psi_{n}(s)\right\} .
$$

For the images

$$
\bar{\xi}_{1 n}(s)=\frac{1}{\left(s-s_{1}\right)\left(s-s_{2}\right)}, \quad \bar{\xi}_{2 n}(s)=\frac{s}{\left(s-s_{1}\right)\left(s-s_{2}\right)}, \quad \bar{\xi}_{3 n}(s)=\frac{s^{2}}{\left(s-s_{1}\right)\left(s-s_{2}\right)}
$$


we have the following originals

$$
\xi_{1 n}(t)=\frac{1}{s_{1} s_{2}}-\frac{e^{s_{1} t}}{s_{1}\left(s_{2}-s_{1}\right)}+\frac{e^{s_{2} t}}{s_{2}\left(s_{2}-s_{1}\right)}, \quad \xi_{2 n}(t)=\frac{e^{s_{2} t}-e^{s_{1} t}}{\left(s_{2}-s_{1}\right)}, \quad \xi_{3 n}(t)=\frac{s_{2} e^{s_{2} t}-s_{1} e^{s_{1} t}}{\left(s_{2}-s_{1}\right)} .
$$

For the images

$$
\bar{\xi}_{4 n}(s)=\frac{1}{l} \sum_{i=1}^{I} p_{s t, i} e^{-\frac{x_{i}}{\nu_{n} l}}\left[\frac{e^{-t_{1 i} s}}{\left(s-s_{1}\right)\left(s-s_{2}\right)}-\frac{e^{-t_{2 i} s}}{\left(s-s_{1}\right)\left(s-s_{2}\right)}\right]
$$

and

$$
\begin{aligned}
\bar{\xi}_{5 n}(s) & =\frac{s+a}{\left(s-s_{1}\right)\left(s-s_{2}\right)} \bar{\Psi}_{n}(s) \\
& =\frac{1}{l} \sum_{j=1}^{J} \frac{q_{j}}{F} e^{-\frac{x_{j}}{\nu_{n} l}}\left[e^{-t_{2 j} s}\left(\bar{\xi}_{2 n}(s)+a \bar{\xi}_{1 n}(s)\right)-e^{-t_{2 j} s}\left(\xi_{2 n}(s)+a \bar{\xi}_{1 n}(s)\right)\right],
\end{aligned}
$$

we have the following originals

$$
\xi_{4 n}(t)=\frac{1}{l} \sum_{i=1}^{I} p_{s t, i} e^{-\frac{x_{i}}{\nu_{n} l}}\left[\left\{\begin{array}{ll}
0, & t<t_{1 i} \\
\xi_{1 n}\left(t-t_{1 i}\right), & t>t_{1 i}
\end{array}-\left\{\begin{array}{ll}
0, & t<t_{2 i} \\
\xi_{1 n}\left(t-t_{2 i}\right), & t>t_{2 i}
\end{array}\right] .\right.\right.
$$

and

$$
\begin{aligned}
\xi_{5 n}(t)=\frac{1}{l} \sum_{j=1}^{J} \frac{q_{j}}{F} e^{-\frac{x_{j}}{\nu_{n} l}}\left[\left\{\begin{array}{ll}
0, & t<t_{1 j} \\
\xi_{2 n}\left(t-t_{1 j}\right)+a \xi_{1 n}\left(t-t_{1 j}\right), & t>t_{1 j}
\end{array}\right.\right. \\
-\left\{\begin{array}{ll}
0, & t<t_{2 j} \\
\xi_{2 n}\left(t-t_{2 j}\right)+a \xi_{1 n}\left(t-t_{2 j}\right), & t>t_{2 j}
\end{array}\right] .
\end{aligned}
$$

Thus we obtain from equality (20)

$$
\tilde{p}_{n}(t)=-\left(\frac{c}{l}\right)^{2} \frac{l}{\nu_{n}}\left[d_{1} \xi_{1 n}(t)+d_{2} \xi_{2 n}(t)+d_{3} \xi_{3 n}(t)\right]-\left(\frac{c}{l}\right)^{2} \frac{l}{\nu_{n}} \xi_{4 n}(t)+c^{2} \xi_{5 n}(t) .
$$

Since the coefficients originals of the expansion series of the pressure function in the series (11) are found, then, based on the additive property of the Laplace-Carson transform, we can assume that the solution of the set problem with regard to pressure is found.

\section{Calculation of gas mass consumption change in stable boundary and initial conditions}

In the final result, the pressure distribution in the pipeline for the accepted boundary conditions is determined by the formula

$$
p(x, t)+\frac{x}{l} h_{p}-p_{0 k}=-2 \sum_{n=1}^{\infty} \operatorname{Im}\left\{\tilde{p}_{n}(t)\right\} \sin \frac{n \pi x}{l},
$$

or

$$
p(x, t)=p_{0 k}-\frac{x}{l} h_{p}-2 \sum_{n=1}^{\infty} \operatorname{Im}\left\{\tilde{p}_{n}(t)\right\} \sin \frac{n \pi x}{l} .
$$

Mathematical Modeling and Computing, Vol. 6, No.1, pp. 116-128 (2019) 
The mass of gas contained in the pipe is determined by the formula

$$
M=\int_{0}^{l} \rho d v, \quad v=F d x, \quad M=F \int_{0}^{l} \rho d x .
$$

Using the state equation to determine the mass, we obtain the formula

$$
M=F \int_{0}^{l} \frac{p}{z R T} d x=\frac{F}{z R T} \int_{0}^{l} p(x, t) d x .
$$

If in the last formula use the relation (22), then we obtain

$$
\begin{aligned}
M_{z s} & =\frac{F l}{z R T} \int_{0}^{t}\left\{p_{0 k}-\frac{x}{l} h_{p}-\frac{2}{\pi} \sum_{n=1}^{\infty} \frac{1-(-1)^{n}}{n} \operatorname{Im}\left\{\tilde{p}_{n}(\tau)\right\}\right\} d \tau \\
& =\frac{F l}{z R T}\left\{\left(p_{0 k}-\frac{x}{l} h_{p}\right) t-\frac{2}{\pi} \sum_{n=1}^{\infty} \frac{1-(-1)^{n}}{n} \operatorname{Im}\left[\int_{0}^{t} \tilde{p}_{n}(\tau) d \tau\right]\right\}
\end{aligned}
$$

If

$$
U_{n}(t)=\int_{0}^{t} \tilde{p}_{n}(\tau) d \tau
$$

then

$$
U_{n}(t)=-\left(\frac{c}{l}\right)^{2} \frac{l}{\nu_{n}}\left[d_{1} U_{1 n}(t)+d_{2} U_{2 n}(t)+d_{3} U_{3 n}(t)\right]-\left(\frac{c}{l}\right)^{2} \frac{l}{\nu_{n}} U_{4 n}(t)+c^{2} U_{5 n}(t) .
$$

In the last formula we introduced the notation

$$
U_{\text {in }}(t)=\int_{0}^{t} \xi_{\text {in }}(\tau) d \tau
$$

Using the definition of functions $\xi_{i n}(t)$, we obtain the formulas

$$
\begin{aligned}
& U_{1 n}(t)=\int_{0}^{t} \xi_{1 n}(\tau) d \tau=\int_{0}^{t}\left[\frac{1}{s_{1} s_{2}}-\frac{e^{s_{1} \tau}}{s_{1}\left(s_{2}-s_{1}\right)}+\frac{e^{s_{2} \tau}}{s_{2}\left(s_{2}-s_{1}\right)}\right] d \tau, \\
& U_{1 n}(t)=\frac{t}{s_{1} s_{2}}-\frac{e^{s_{1} t}-1}{s_{1}^{2}\left(s_{2}-s_{1}\right)}+\frac{e^{s_{2} t}-1}{s_{2}^{2}\left(s_{2}-s_{1}\right)}, \\
& U_{2 n}(t)=\int_{0}^{t} \frac{e^{s_{2} \tau}-e^{s_{1} \tau}}{\left(s_{2}-s_{1}\right)} d \tau=\frac{1}{s_{2}-s_{1}}\left[\frac{1}{s_{2}}\left(e^{s_{2} t}-1\right)-\frac{1}{s_{1}}\left(e^{s_{1} t}-1\right)\right], \\
& U_{3 n}(t)=\int_{0}^{t} \frac{s_{2} e^{s_{2} \tau}-s_{1} e^{s_{1} \tau}}{\left(s_{2}-s_{1}\right)} d \tau=\frac{1}{s_{2}-s_{1}}\left[e^{s_{2} t}-e^{s_{1} t}\right],
\end{aligned}
$$

Further

$$
\begin{gathered}
U_{4 n}(t)=\frac{1}{l} \sum_{i=1}^{I} p_{s t, i} e^{-\frac{x_{i}}{\nu_{n} l}}\left[\left\{\begin{array}{ll}
0, & t<t_{1 i} \\
U_{1 i n 1}\left(t-t_{1 i}\right), & t>t_{1 i}
\end{array}-\left\{\begin{array}{ll}
0, & t<t_{2 i} \\
U_{1 i n 2}\left(t-t_{2 i}\right), & t>t_{2 i}
\end{array}\right],\right.\right. \\
U_{5 n}(t)=\frac{1}{l} \sum_{j=1}^{J} \frac{q_{j}}{F} e^{-\frac{x_{j}}{\nu_{n} l}}\left[\left\{\begin{array}{ll}
0, & t<t_{1 j} \\
U_{2 j n 1}\left(t-t_{1 j}\right)+a U_{1 j n 1}\left(t-t_{1 j}\right), & t>t_{1 j}
\end{array}\right.\right. \\
-\left\{\begin{array}{ll}
0, & t<t_{2 j} \\
U_{2 j n 2}\left(t-t_{2 j}\right)+a U_{1 j n 2}\left(t-t_{2 j}\right), & t>t_{2 j}
\end{array}\right],
\end{gathered}
$$

Mathematical Modeling and Computing, Vol. 6, No. 1, pp. 116-128 (2019) 
where

$$
\begin{aligned}
& U_{1 j n i}(t)=\frac{t-t_{i j}}{s_{1} s_{2}}-\frac{e^{s_{1} t}-e^{s_{1} t_{i j}}}{s_{1}^{2}\left(s_{2}-s_{1}\right)}+\frac{e^{s_{2} t}-e^{s_{2} t_{i j}}}{s_{2}^{2}\left(s_{2}-s_{1}\right)}, \\
& U_{2 j n i}(t)=\frac{1}{s_{2}-s_{1}}\left[\frac{1}{s_{2}}\left(e^{s_{2} t}-e^{s_{2} t_{i j}}\right)-\frac{1}{s_{1}}\left(e^{s_{1} t}-e^{s_{1} t_{i j}}\right)\right] .
\end{aligned}
$$

Thus, the gas mass in the pipeline is calculated by the formula

$$
M_{z s}=\frac{F l}{z R T}\left\{\left(p_{0 k}-\frac{x}{l} h_{p}\right) t-\frac{2}{\pi} \sum_{n=1}^{\infty} \frac{1-(-1)^{n}}{n} \operatorname{Im} U_{n}(t)\right\} .
$$

Let us convert the last expression so that it can be used to detect gas leaks

$$
\begin{aligned}
M_{z s}= & \frac{F l}{z R T}\left[\left(p_{0 k}-\frac{x}{l} h_{p}\right) t\right]+\frac{2 F c^{2}}{\pi z R T} \sum_{n=1}^{\infty} \frac{1-(-1)^{n}}{n} \operatorname{Im}\left\{\frac{1}{\nu_{n}}\left[d_{1} U_{1 n}(t)+d_{2} U_{2 n}(t)+d_{3} U_{3 n}(t]\right\}\right. \\
& -\frac{2 F c^{2}}{\pi z R T} \sum_{n=1}^{\infty} \frac{1-(-1)^{n}}{n} \operatorname{Im}\left\{\frac{1}{\nu_{n}} U_{4 n}(t)+c^{2} U_{5 n}(t)\right\} .
\end{aligned}
$$

The analysis of the last formula shows that the value of the dimension leakage $\left(p, q, t_{1}, t_{2}\right)$ is calculated by the terms $U_{4 n}(t)$ and $U_{5 n}(t)$. It is obvious that, in order to detect the availability of gas sources and drains, it is necessary that the contribution of these two terms is greater than the calculation error, and this will depend on the volume $q_{j}$ and change of the pressure in the vicinities of sources and drains $p_{s t, i}$ and on the time $t$.

Let us introduce the designations:

$$
M_{z s 1}=\frac{F l}{z R T}\left[\left(p_{0 k}-\frac{x}{l} h_{p}\right) t\right]+\frac{2 F c^{2}}{\pi z R T} \sum_{n=1}^{\infty} \frac{1-(-1)^{n}}{n} \operatorname{Im}\left\{\frac{1}{\nu_{n}}\left[d_{1} U_{1 n}(t)+d_{2} U_{2 n}(t)+d_{3} U_{3 n}(t]\right\}\right.
$$

and

$$
M_{z s 2}=-\frac{2 F c^{2}}{\pi z R T} \sum_{n=1}^{\infty} \frac{1-(-1)^{n}}{n} \operatorname{Im}\left\{\frac{1}{\nu_{n}} U_{4 n}(t)+c^{2} U_{5 n}(t)\right\}
$$

\section{Scheme of the algorithm for determining the parameters of sources and drains on the section of the gas pipeline}

To determine the parameters of the sources and drains of gas it is necessary to set the following parameters: coordinates $x$; volumes $q$; the pressures behavior in their vicinities $p$ and the time of appearance $t_{1}$ and the time of end $t_{2}$.

The algorithm for determination of parameters of gas sources and drains.

1. According to the given input data, the gas masses $M_{z s 1}$ and $M_{z s 2}$ at different moments of time and the difference $\Delta M=M_{z s 1}\left(t_{2}\right)-M_{z s 1}\left(t_{1}\right)$ are calculated.

2. If $\Delta M_{z a m}$ is the measured change of gas mass over a period of time $t \in\left[t_{1}, t_{2}\right]$ and $\mid \Delta M_{z a m}-$ $\Delta M \mid \leqslant \varepsilon$, where $\varepsilon$ is the model accuracy, then it can be argued with a high probability that there are no sources and drains in the time interval $t \in\left[t_{1}, t_{2}\right]$.

3. If $\left|\Delta M_{z a m}-\Delta M\right|>\varepsilon$ then the sources and drains parameters are determined from the systems of equations, which are based on the ratio (23) according to known values $M_{z s 2}\left(t_{i}\right), i=\overline{1, I}$. Moreover, the value $I$ should be not less than the number of sources and drains parameters.

4. To determine the sources and drains parameters firstly it's necessary to refine the model parameters on the basis of inverse coefficient problems solving. To do this, the obtained solution of the formulated boundary value problem considering $p_{s t, i}$ and $q_{j}(t)$ equal to zero can be used. 
In isothermal mode neglecting Coriolis force provided averaging the value of the compressibility coefficient $z$ system (1) will look like [10-12]

$$
\left\{\begin{array}{l}
\frac{\partial \omega}{\partial t}+\frac{\partial p}{\partial x}+a \omega-b p=0 \\
\frac{\partial \omega}{\partial x}+\frac{1}{c^{2}} \frac{\partial p}{\partial t}=0
\end{array}\right.
$$

If $U_{4 n}(t)$ and $U_{4 n}(t)$ are aqual to zero then the solution of the last system for given boundary conditions is obtained from the formula (23). Parameters of the mathematical model are refined according to experimental data. We can judge about the presence of gas leaks from the pipeline in that case when the difference between the corresponding parameters will be greater than the accuracy of the models.

\section{Numerical experiment}

Modeling the subsystem GTS - gas consumption measurement point (GCMP) Khodovychi (pipe with a diameter of $1400 \mathrm{~mm}$ ) - CS Dolyna was carried out. The estimated technological scheme of the subsystem GTS GCMP Khodovychi - CS Dolyna is presented in Fig. 1. The results of modeling are presented in Figs. 2, 3 and in Table 1.

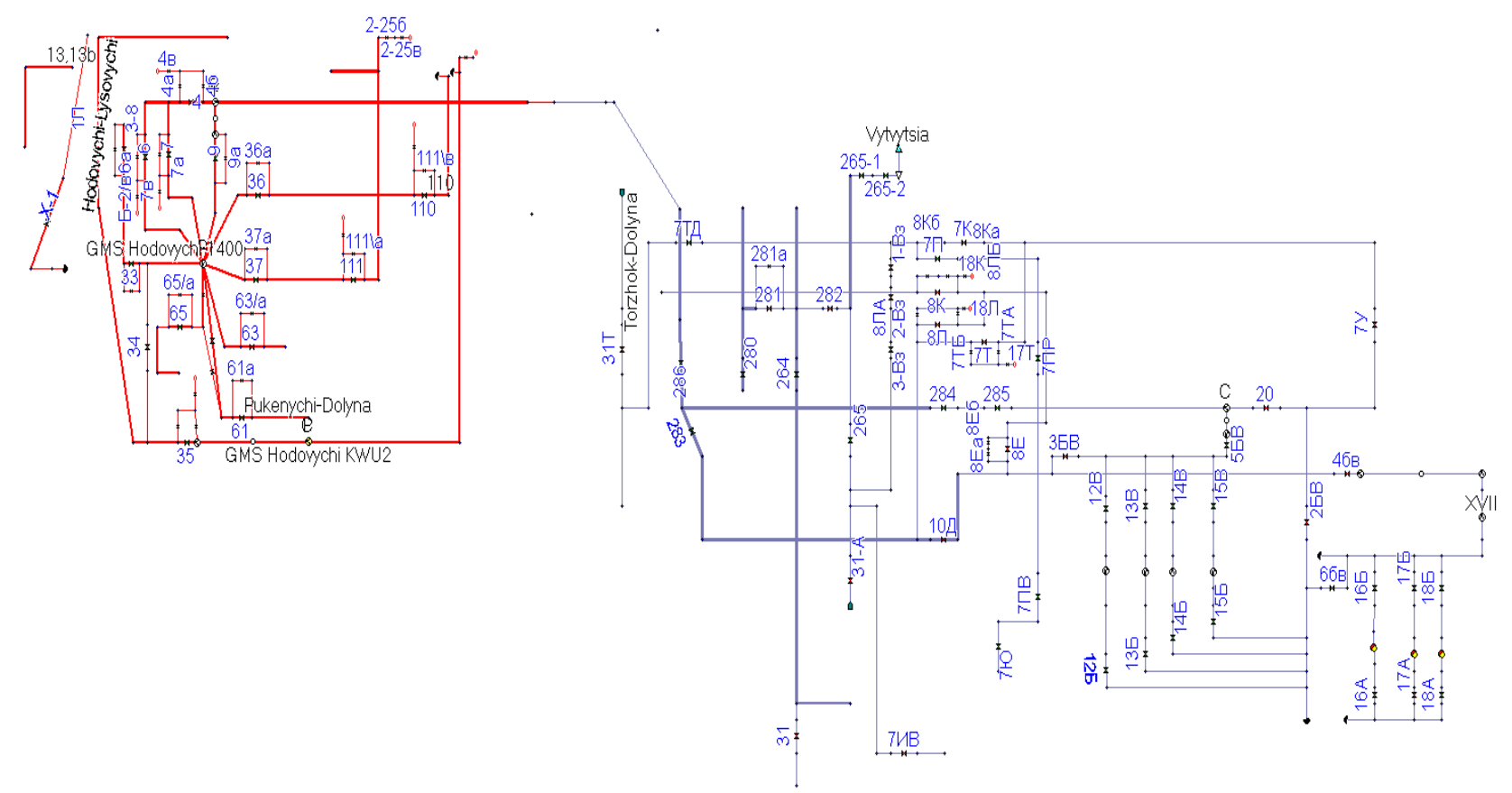

Fig. 1. The technological scheme of the section GCMP Khodovychi - CS Dolyna.

The data for calculation is taken for the period of time 20.05.2018 - 18.06.2018. The numerical experiment was as follows.

The consumption change, the pressure change, the temperature change, gas density change over time (during the period of 20.05.2018 - 18.06.2018) in the GCMP Khodovychi and the consumption change, the pressure change, the temperature change at all points of exit from subsystems are known values.

To calculate the non-stationary gas flow, pressure measurements on the CS Dolyna and gas consumption at all other points of the gas flow inlet (outlet) are used. The pressure change on the GCMP Khodovychi and the consumption change over the time on the CS Dolyna are analyzed. If the pressure 
change over the time on the GCMP Khodovychi coincides with the measured data then it means that the model of the non-stationary gas flow is adequate. For the entire period of time (except for periods of significant non-stationary processes), the absolute value of the calculated consumption is greater than the measured consumption (the green diagram is located below the red diagram).

The carried out analysis has shown that there is a insignificant systematic error of the gas consumption measurement.

Table 1. The results of the gas flow modeling on the section GTS GCMP Khodovychi - CS Dolyna.

\begin{tabular}{|c|c|c|c|c|c|}
\hline Date & $\begin{array}{c}\text { Measurement } \\
\text { Khodovychi, } \\
\text { thousands } \\
\mathrm{m}^{3} \text { per day }\end{array}$ & $\begin{array}{c}\text { Measurement } \\
\text { Dolyna, } \\
\text { thousands } \\
\mathrm{m}^{3} \text { per day }\end{array}$ & $\begin{array}{c}\text { Gas reserve, } \\
\mathrm{m}^{3}\end{array}$ & $\begin{array}{c}\text { Gas reserve } \\
\text { change, } \\
\text { thousands } \\
\mathrm{m}^{3}\end{array}$ & $\begin{array}{c}\text { Imbalance, } \\
\%\end{array}$ \\
\hline 20.05 .2018 & 8848.568 & 8839.568 & 3191549 & & \\
\hline 21.05 .2018 & 10416.42 & 10708.422 & 3559580 & 368.03 & -0.71 \\
\hline 22.05 .2018 & 23373.29 & 23308.285 & 3470986 & -88.59 & 0.10 \\
\hline 23.05 .2018 & 22391.18 & 22398.184 & 3499092 & 28.11 & -0.09 \\
\hline 24.05 .2018 & 21659.32 & 21516.317 & 3289746 & -209.35 & 0.31 \\
\hline 25.05 .2018 & 14417.03 & 14538.03 & 3488052 & 198.31 & -0.53 \\
\hline 26.05 .2018 & 12566.45 & 12528.445 & 3439700 & -48.35 & 0.08 \\
\hline 27.05 .2018 & 12280.81 & 12238.806 & 3386243 & -53.46 & 0.09 \\
\hline 28.05 .2018 & 12025.05 & 12019.053 & 3370600 & -15.64 & 0.08 \\
\hline 29.05 .2018 & 11770.26 & 11780.257 & 3401173 & 30.57 & -0.17 \\
\hline 30.05 .2018 & 13529.38 & 13554.318 & 3441904 & 40.73 & -0.12 \\
\hline 31.05 .2018 & 13914.04 & 13852.036 & 3347302 & -94.60 & 0.24 \\
\hline 01.06 .2018 & 13004.79 & 12978.786 & 3318344 & -28.96 & 0.02 \\
\hline 02.06 .2018 & 13038.36 & 13042.36 & 3326189 & 7.84 & -0.03 \\
\hline 03.06 .2018 & 12829.38 & 12825.383 & 3318652 & -7.54 & 0.03 \\
\hline 04.06 .2018 & 15006.71 & 15034.712 & 3346041 & 27.39 & 0.00 \\
\hline 05.06 .2018 & 12737.14 & 12691.144 & 3279972 & -66.07 & 0.16 \\
\hline 06.06 .2018 & 12748.68 & 12757.675 & 3282252 & 2.28 & 0.05 \\
\hline 07.06 .2018 & 13854.72 & 13839.715 & 3295885 & 13.63 & -0.21 \\
\hline 08.06 .2018 & 15480.06 & 15493.056 & 3311435 & 15.55 & -0.02 \\
\hline 09.06 .2018 & 13204.42 & 13225.421 & 3349365 & 37.93 & -0.13 \\
\hline 10.06 .2018 & 13154.89 & 13183.89 & 3387645 & 38.28 & -0.07 \\
\hline 11.06 .2018 & 17617.44 & 17605.436 & 3351812 & -35.83 & 0.14 \\
\hline 12.06 .2018 & 21360.91 & 21355.909 & 3349762 & -2.05 & -0.01 \\
\hline 13.06 .2018 & 21560.55 & 21559.548 & 3349049 & -0.71 & 0.00 \\
\hline 14.06 .2018 & 20734.96 & 20700.961 & 3306379 & -42.67 & 0.04 \\
\hline 15.06 .2018 & 19565.1 & 19592.097 & 3344006 & 37.63 & -0.05 \\
\hline 16.06 .2018 & 19445.77 & 19435.77 & 3337088 & -6.92 & -0.02 \\
\hline 17.06 .2018 & 19631.76 & 19649.755 & 3360566 & 23.48 & -0.03 \\
\hline 18.06 .2018 & 18476.59 & 18457.589 & 3330682 & -29.88 & 0.06 \\
\hline & & & & & \\
\hline
\end{tabular}

As a result of modeling of the non-stationary mode of gas transportation, the distribution of the accumulated volume at the given time period is obtained. Taking into account the daily consumption data in all objects of the subsystem and the gas reserve change per every day of the selected time period, we calculate the distribution of the imbalance over the time of modeling and the imbalance over the entire period of time. The average magnitude of the imbalance in the subsystem GCMP Khodovychi - CS Dolyna during the period of time from 20.05.2018 to 18.06.2018 is $0.014 \%$.

In the figures below the time $t$ is set in hours, the pressure $P(t)$ is set in $\mathrm{kg} / \mathrm{cm}^{2}$, and the consumption $P(t)$ is set in million $\mathrm{m}^{3}$ per day.

Note that in the figures the red color corresponds to the measured values, and the green color corresponds to the calculated values. The estimation of the methane volumes emission with leakages has 


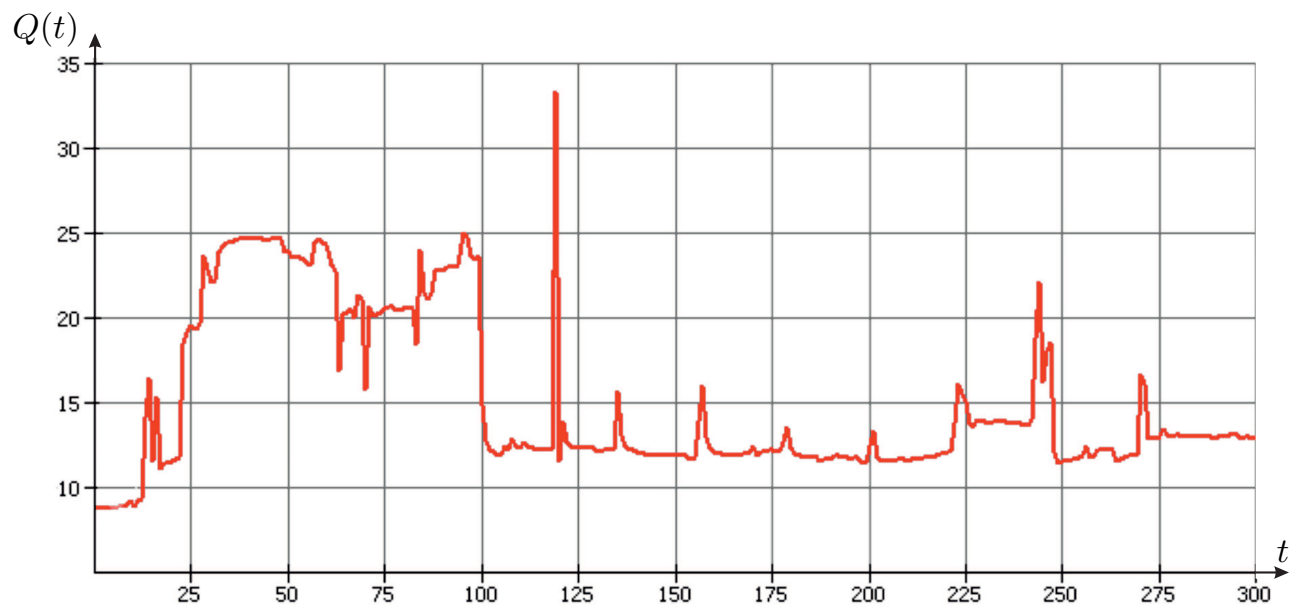

Fig. 2. The measured and calculated gas flow rate values on GCMP Khodovychi 1400.

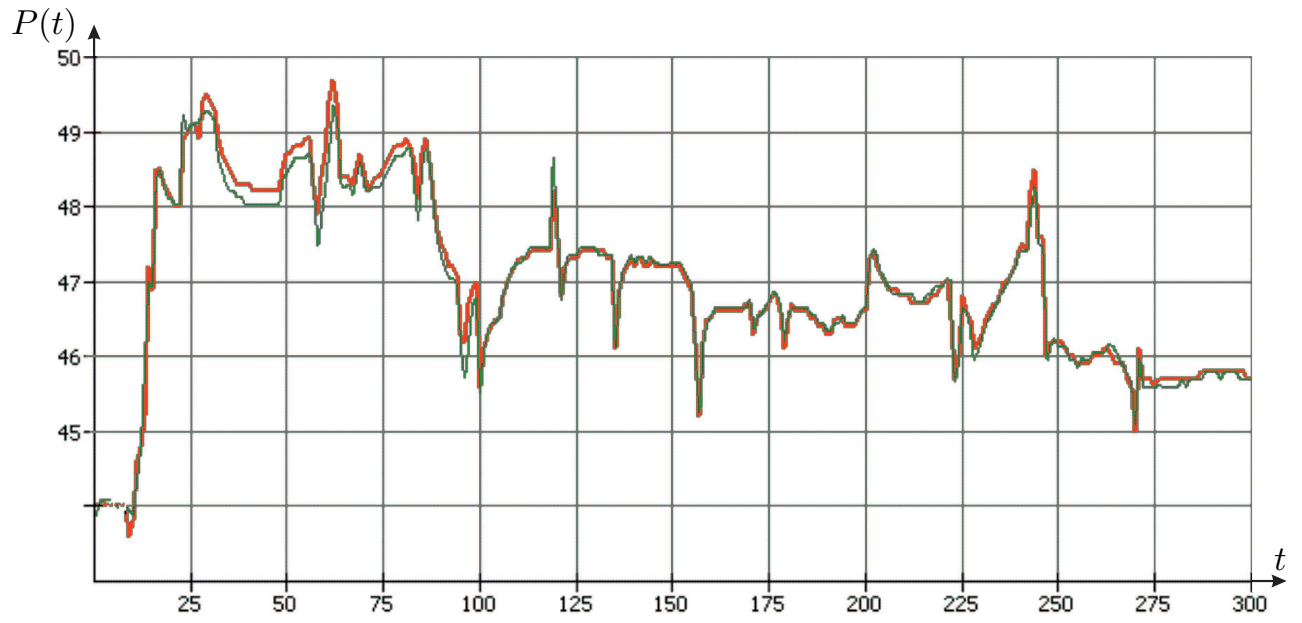

Fig. 3. The measured pressure values on GCMP Khodovychi 1400.

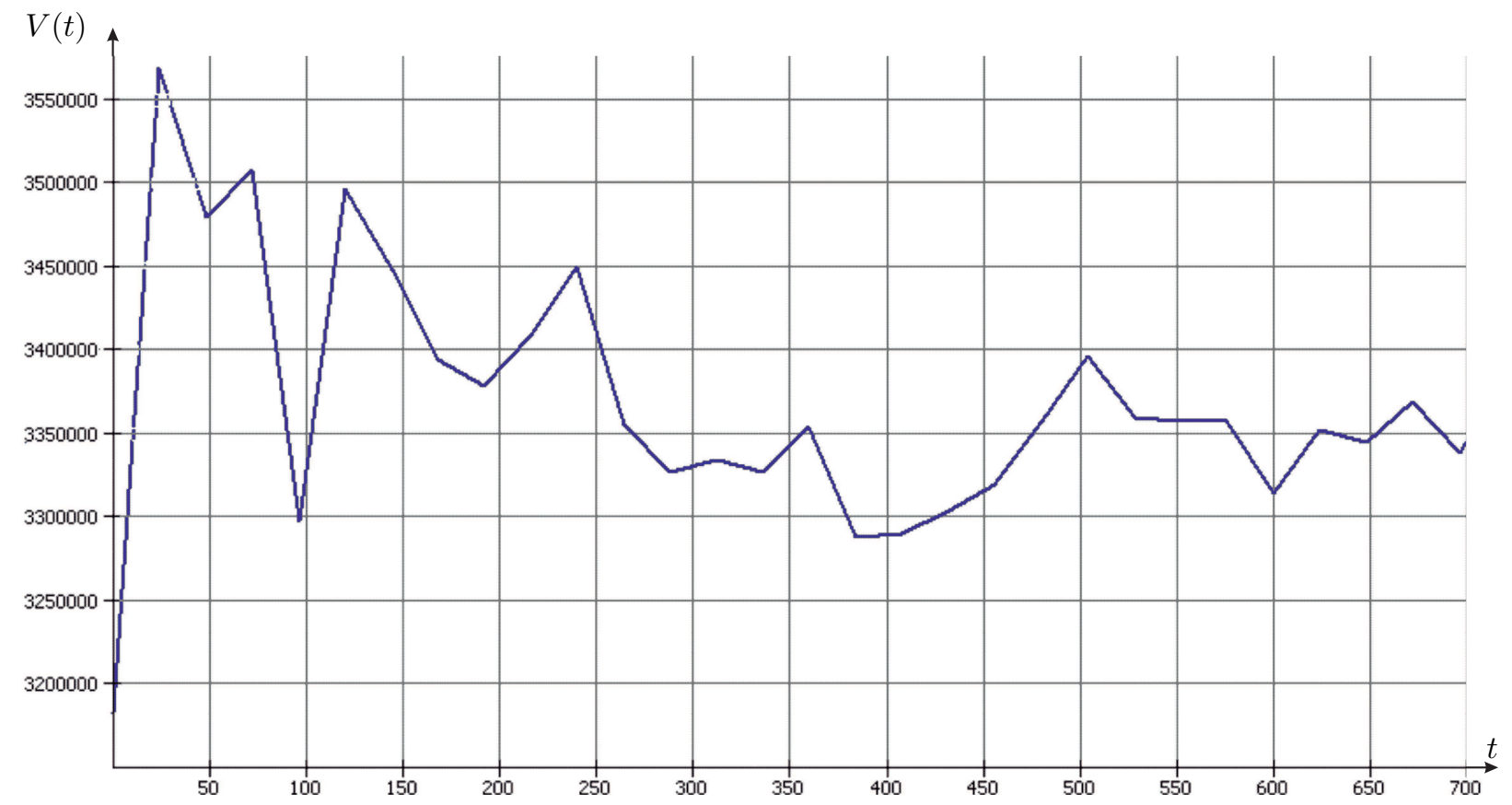

Fig. 4. The volume change of accumulated gas over time on the section GCMP Hodovichi - CS Dolyna. 
shown that the volume of leakages in general does not exceed $0.33 \%$ of the volumes of gas transportation by the system of main gas pipelines, and for separate gas transport objects, where instrumental researches are carried out, is not more than $0.01 \%$ of the volumes of transported gas by this object. The volumes of the imbalance include probable systematic errors of flowmeters.

\section{Conclusions}

The leakages share in the gas unbalance in the GTS due to its bad tightness is different. It essentially depends both on the value of the time interval at which the volumes of leakages are estimated and on the method of calculating the volumes accumulated in the objects of the GTS. In turn, the completeness and the accuracy of the input data for the calculation method depend on the quality of metrological support. The share of leaks in the daily gas imbalance in the GTS is roughly $15-30 \%$, and in the annual balance it is $2-4 \%$. It is problematic to estimate the leakages volumes at the daily time interval, because its value is commensurate with the accuracy of the current metrological support. At the objects of the GTS, because of their significant wear and tear, there are abnormal situations, resulting in loss of significant volumes of gas. So, to locate leaks in such situations, we need the cheapest but effective means - algorithmic methods.

[1] Navarro A., Begovich O., Sánchez J., Besancon G. Real-Time Leak Isolation Based on State Estimation with Fitting Loss Coefficient Calibration in a Plastic Pipeline. Asian Journal of Control. 19, 255-265 (2017).

[2] Murvay P. S., Silea I. A. Survey on gas leak detection and localization techniques. Journal of Loss Prevention in the Process Industries. 25, 966-973 (2012).

[3] Asgari H. R., Maghrebi M.F. Application of nodal pressure measurements in leak detection. Flow Measurement and Instrumentation. 50, 128-134 (2016).

[4] Tao W., Dongying W., Yu P., Wei F. Gas leak localization and detection method based on a multi-point ultrasonic sensor array with TDOA algorithm. Measurement Science and Technology. 26 (2), 095002 (2015).

Daneti M. On using double power spectral density information for leak detection. 2013 IEEE International Conference on Industrial Technology (ICIT), Cape Town. 1162-1167 (2013).

[5] Ekuakille A. L., Vergallo P. Decimated signal diagonalization method for improved spectral leak detection in pipelines. IEEE Sensors Journal. 14 (6), 1741-1748 (2014).

[6] Hou C. X., Zhang E. H. Pipeline leak detection based on double sensor negative pressure wave. Applied Mechanics and Materials. 313, 1225-1228 (2013).

[7] Akopova G., Dorokhova E., Popov P. Estimation of volumes of methane losses with leaks from the technological equipment of gas transportation objects of USO "Gazprom". Scientific-technical collection of News Gas Science. 2 (13), 63-67 (2013).

[8] Pyanylo Ya. D., Prytula M. G., Prytula N. M. Models of mass transfer in gas transmission systems. Mathematical modeling and computing. 1 (1), 84-96 (2014).

[9] Pyanylo Ya., Prytula M., Prytula N. Mathematical models of unstable gas motion in objects of gas transmission systems. Physical-mathematical modeling and informational technologies. 4, 69-77 (2006).

[10] Altshul A. D. Hydraulic resistance. Moscow, Nedra (1982), (in Russian).

[11] Sinchuk Yu., Prytula N., Prytula M. Modeling of non-stationary modes of gas networks. Bulletin of Lviv Polytechnic National University. Computer Sciences and Informational Technologies. 663, 128-132 (2010).

[12] Ditkin V., Prudnikov A. Handbook of operational calculus. Moscow, High school (1965), (in Russian). 


\title{
Про один інваріант моделі нестаціонарного газового потоку в трубопроводах
}

\author{
П'янило Я. ${ }^{1}$, Притула . $^{2}$, Притула M. ${ }^{2}$, Химко О. ${ }^{1}$ \\ ${ }^{1}$ Центр математичного моделювання \\ Інституту прикладних проблем механіки і математики \\ ім. Я. С. Підстригача НАН України, \\ вул. Дю. Дудаєва, 15, Лъвів, 79005, Україна \\ ${ }^{2}$ Відділ розробки систем оптимального планування та прогнозування режимів роботи ГТС, \\ Філія "Науково-дослідний інститут транспорту газу" ПАТ "Укртрансгаз", \\ вул. Конева, 16, Харків, 61004, Україна
}

Розглянуто проблему аналізу балансу газу в об'єктах газотранспортної системи та фактори впливу на точність його встановлення. Показано, що проблему точності розрахунку окремих балансових показників можна ефективно розв'язати, використовуючи встановлені інваріанти математичної моделі руху газу. Проведені числові експерименти підтвердили достатню точність запропонованого підходу.

Ключові слова: баланс газу, герметичність газопроводу, алгоритмічний спосіб, витоки газу, математична модель руху газу.

2000 MSC: $76 \mathrm{~N} 25,49 \mathrm{~J} 20$

УДК: $622.692 .4+622.691 .24$ 